\title{
Editorial
}

\section{Quem Nutre? \\ Uma pesquisa sobre as EMTNs do Brasil}

\section{Who Nourishes? Research on Brazilian EMTNs}

Esse editorial tem esse título devido a um relevante estudo publicado neste número. Quem Nutre? Uma pesquisa sobre as EMTNs do Brasil. Campos e colaboradores (que reúne um grupo de pesquisadores da BRASPEN) respondem a essa excelente pergunta. A resposta, contida no artigo, traz um retrato das EMTNs no nosso País. Como se sabe, a implementação de EMTNs em hospitais brasileiros é obrigatória, segundo a Agência Nacional de Vigilância Sanitária (ANVISA), desde a publicação da portaria 272 de 1998. O estudo demonstra, entretanto, a inquietante constatação que não há EMTN em todos os hospitais. Entretanto, quem somos afinal de contas? Isso tudo parece ainda mais relevante quando constatamos que, apesar de todos os esforços da BRASPEN e de outras Sociedades para a evolução da terapia nutricional no Brasil, a prevalência da desnutrição hospitalar ainda permanece alta. O fato é: EMTNs ainda não são uma realidade no País. Quais as razões de uma portaria com mais de 20 anos ainda não ser cumprida na íntegra? Penso que esses dados devam trazer essa discussão para a BRASPEN e, como Sociedade, ela deve propor estratégias para redução desse "gap" ao Governo Federal. Finalmente, parabenizo os autores pelo estudo e pelos relevantes dados aqui apresentados. Penso que a leitura do artigo é obrigatória aos nossos leitores.

\section{José Eduardo de Aguilar-Nascimento}

Editor 